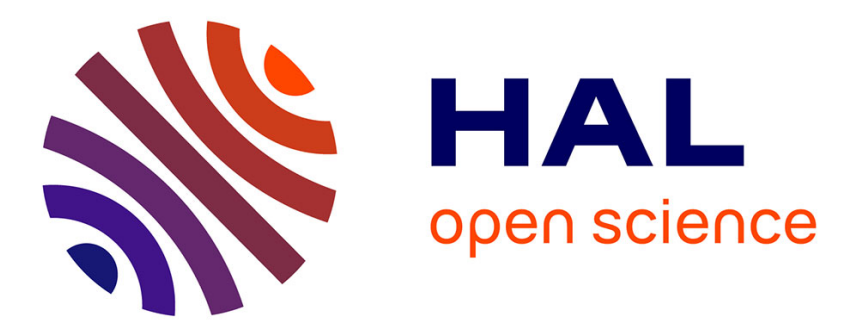

\title{
Supporting Professional Transitions in Innovative Projects
}

\author{
Valérie Pueyo, Pascal Beguin
}

\section{To cite this version:}

Valérie Pueyo, Pascal Beguin. Supporting Professional Transitions in Innovative Projects. Advances in Intelligent Systems and Computing, 2019, Proceedings of the 20th Congress of the International Ergonomics Association (IEA 2018), 824, pp.1949-1957. 10.1007/978-3-319-96071-5_204. halshs01960803

\section{HAL Id: halshs-01960803 https://shs.hal.science/halshs-01960803}

Submitted on 15 Jan 2019

HAL is a multi-disciplinary open access archive for the deposit and dissemination of scientific research documents, whether they are published or not. The documents may come from teaching and research institutions in France or abroad, or from public or private research centers.
L'archive ouverte pluridisciplinaire HAL, est destinée au dépôt et à la diffusion de documents scientifiques de niveau recherche, publiés ou non, émanant des établissements d'enseignement et de recherche français ou étrangers, des laboratoires publics ou privés. 


\title{
Supporting professional transitions in innovative
}

\section{projects}

\author{
Valérie Pueyo ${ }^{1}$ and Pascal Béguin ${ }^{1}$ \\ ${ }^{1}$ University Lyon 2, EVS UMR 5600, IMU Lyon, France \\ Valerie.pueyo@gmail.com, pascal.daniel.beguin@gmail.com
}

\begin{abstract}
Our work focuses on the professional transitions required to address the issues and meet the challenges of sustainable development. We see sustainable development as something that has to be thought out, especially in terms of work activities (to the extent that there will be no sustainability without workers being able to implement it in their work). After having indicated the depth of the changes requested and the corresponding design regime, we make two proposals that are intended to support the professional transitions required by the transition to more sustainable forms of production: namely (i) the implementation of a step-by-step design, and (ii) the creation of a work observatory whose operating methods are described.
\end{abstract}

Keywords: innovation, work, activity, design, sustainable development.

\section{Introduction}

This paper is part of current thinking on "work in transition". In Europe this subject has received attention since the 1990s, in a context of a restructuring of production systems due to globalisation and the emergence of new technologies, and the joint appearance of deregulation of the labour market and often precarious jobs (now called the Uberisation of labour). In this context, much of the work is devoted to the following dimensions: economic (labour market developments [1]), legal (developments in labour law and social protection [2]), and socio-economic (e.g. challenges stemming from the economic crisis). (e.g. reclassification of workers or changes in vocational training policies, etc.) [3]),

Without denying the interest of this work (given the impact of these developments on the European social model), we believe that questions relating to work in transition should be examined from the point of view not only of employment or social relations, but also of work understood as an activity (i.e. as a goal-oriented action, implemented by a human actor and not a "human factor", and situated in a professional organizational, technical and social - context ([4], [5], [6]). The technical and organizational changes affecting workplaces in all sectors are not limited to socioeconomic dimensions; we are also witnessing the emergence of varying degrees of 
radical innovations that are essentially technological (e.g. artificial intelligence) or organisational (e.g. fablab, living lab, etc.). This raises questions relating to the transformation of professional, individual and collective practices, and which call for the development of renewed working practices.

It is in this context that for several years we have been conducting a series of interventions and research focused on professional transitions, in the context of profound changes related to the issues and challenges of sustainable development [agricultural production - [7]; water management - [8] or waste management - [9]; energy efficiency $-[10]$.

This work is based on three principles within our own research tradition (in the ergonomics of activity):

- First, labour issues are not sufficiently taken into account in transfers. A central idea in the ergonomics of activity is that work-related issues should not be seen only as adjustment variables, as is all too often the case. In production environments, decisions are essentially made on the basis of technological (e.g. machine selection) or economic (e.g. productivity indicators) considerations. As a result, work is a residual variable: workers are expected to adapt or align with economic and technical choices. We believe, on the other hand, that work must be considered as a resource for identifying, building and implementing possible changes. For example, there will be no sustainable agriculture without farmers being able to implement it during their work.

- Secondly, due to our concern (living, social and cultural activity), we favour an intrinsic approach to work (as opposed to an extrinsic approach). The intrinsic approach seeks to see things from the perspective of the person or persons engaged in a professional act - what they see as meaningful, what they seek to do, the difficulties they encounter in doing so - and not from the perspective of the task (extrinsic approach). This distinction (see also [6]) is close to that of Norman [11] between "personal view" and "system view", and of Lomov [12] between "anthropocentric" and "technocentric". In the face of change, the intrinsic approach seeks to understand professional transitions: how and why competent practitioners, intentionally and interactively keep interpreting and reinterpreting the multiple, changing, and often unpredictable challenges and tasks they face, and the extent to which they are changing, adapting and developing their own activities and resources (cognitive or technical) on that basis.

- The two preceding principles (work as a resource and the intrinsic approach) raise questions on the place occupied by the work and activity of the protagonists in manufacturing the transformations under way. From this perspective, we are interested in the place of professional transitions within design dynamics during which changes - i.e. transformations of the work system - are conceived, specified and implemented. The inclusion of professional transitions in the design sciences is consistent with the definition of ergonomics (ergonomics is a profession "that applies theory, principles, 
data and methods to design in order to optimize human well-being and overall system performance"), and as such aggregates a whole body of research conducted in the ergonomics of project management (see for example [4]). On the other hand, this position integrates the two previous principles (work as a resource and the intrinsic approach) when the design approach mobilizes participatory approaches.

In the remainder of this text, we characterize the nature of the design processes associated with changes, and identify the dimensions that we feel are characteristic of professional transitions. Finally, we define the contributions that we seek to make as ergonomists

\section{Innovative design and development of professional worlds}

In order to incorporate changes in work in design science, the distinction proposed by Meynard \& Coll. [13] between regulated design and innovative design can be used. When the design is set, the performance criteria are known, the success criteria are stabilized, the expertise is well identified and the procedures are tested. The actors learn in order to face the singularity of a given project (any action reconstructs the knowledge it needs, as constructivist epistemologies have amply shown). But this learning takes place by exploiting available resources in a stabilized framework. In innovative design on the other hand, it is this framework that is called into question because it has become unsuitable: new criteria for success must be developed, new resources (tangible and intangible) and new expertise that are well adapted to the needs or constraints encountered. ${ }^{1}$

If we seek to understand innovative design in terms of activity, we believe that it requires the development of professional worlds. It is not possible in this article to exhaustively present the concept of the professional world, which is based on the work of Cassirer and Foucault [16]. We will only point out that the reality of a situation is always too broad to be captured from a single point of view. Moreover, a competent operator withholds very little information in a situation, but this information is operative with regard to the aims of the action. As a result, it is possible to have very different seizures of the same professional reality. Bucciarelli [17] for example has clearly shown the importance of this differentiated capture of reality in the work of designers: what a safety engineer calls "an emergency stop button" will be called by an electrician "a junction box". Faced with the same situation, a person retains only what

1 Note that this distinction between regulated design and innovative design can be mobilised from a perspective that calls for the generalization of innovative design as a response to the economic challenges of innovation (see e.g. [14]). From our point of view, innovative design consists in dealing with a change of "technical paradigm" in Constant's sense (see in this respect [15]). 
is relevant according to their aims, and they mobilise different concepts, procedures and value systems that correspond to them. These axiological, conceptual and practical dimensions are very largely implicit (the actors are not always aware of them), they constitute a background articulated to what the action is about (and which is designated as the object of the action, [18]). What is called a professional world is therefore $a$ set of axiological, conceptual and practical things that are implicit and which form a system with the object of the action [16].

Yet, what characterises innovative design in terms of work activity, is a process of deconstruction-reconstruction of professional worlds called development. An example from the agricultural sector will be used to set ideas. In the agricultural sector, the concept of design had been generally resolved since the 30s and 40s: intensive production based on the use of inputs and on varietal and animal breeding. A great deal of learning, adjustment and effort has been made within this framework. But sustainable development issues require farmers to change their outlook. Intensive cultivation is based on what one would be tempted to describe as a "virile strategy" of the control of the living: we want to manufacture nature by controlling the factors in its cultivation (thanks to the use of inputs: phytosanitary, fertilizers, etc.) or its breeding (by modifying the living). And we have to learn a lot to get there. But agricultural work practices (cultivation or breeding) - which are more respectful of the environment - most often involve a different relationship with the environment. The virile relationship is no longer appropriate: it is rather a question of intervening by touch so that the living that we have goes where we want it to go. But this changes everything, we have to change our professional world: redefine what the action is about, redefine concepts and indicators, as well as resources (cognitive, procedural - e.g., the way in which we work). The goal is to redefine what is important.

Beyond the conceptual dimensions proposed here, it is ultimately the nature and especially the depth of the designated changes that is important:

- A large part of the design process has been completed. But when a change is necessary, an innovative design must be implemented, insofar as the challenge lies less in specifying a solution than in redefining the bases and principles from which we design and act.

- Consequently, it is not enough for actors to learn within frameworks of thought and action (i.e. a professional world) already in place. Indeed, it is less a learning process than a development of the domain of the conceivable and the feasible that is required. It is this morphogenesis of the professional worlds that we call professional transitions. And it is obviously a long and costly process for the protagonists.

This means that changes in work call for specific design approaches (and in any case distinct from those implemented in the regulated design), and that professional transitions are far from being easy for the actors concerned. 


\section{$3 \quad$ An experienced based design}

The distinction between regulated and innovative design reflects two distinct design regimes. But it says nothing about the action rationales to be implemented or the role that professional transitions can play as a resource. Our core premise is that to contribute to the innovative design process it is necessary to focus on an experience development and building curve (rather than reducing uncertainty surrounding technical protocol, as is the case in regulated design). The sections below set out two proposals to this end.

\subsection{Step-by-step design}

The first proposal is to implement a "step-by-step design". In order to describe this form of project management, we need to clarify our understanding of design:

- Design is a goal-oriented process: starting from an initial intention, a desire for the future, an end-in-view that results from unrest or dissatisfaction, its end goal is to set a concrete transformation in motion. The changes taking place in the context of sustainable development are no exception: the reduction of energy efficiency or sustainable farming are desires for a future to bring about. Change therefore requires a transition which, starting from a goal or a project, will lead to the implementation of original and new solutions.

- This transition, however, is caught in a tension between two forces (which need to converge): on the one hand the desirable and on the other the possible. Projects set out an intention from which a desirable forms, one or several elements of possible solutions. But these elements of solutions can meet resistance and may prove possible or impossible. D. Schön's famous metaphor [19] of a "dialogue with the situation", which according to him is characteristic of design, attests to this tension between the desirable and the possible: the designer, striving towards an end goal, projects ideas and knowledge, but the situation "responds" to them, it puts up resistance or offers unexpected potentialities which lead to changes to what was initially desirable.

As a generalisation, to design is to ensure a transition between a desire for the future and a concrete transformation, by interfacing two poles: the desirable and the possible. And the challenge is to make these two poles converge, short of which a concrete transformation informed by the initial end in view can never be reach (see Fig. 1). 


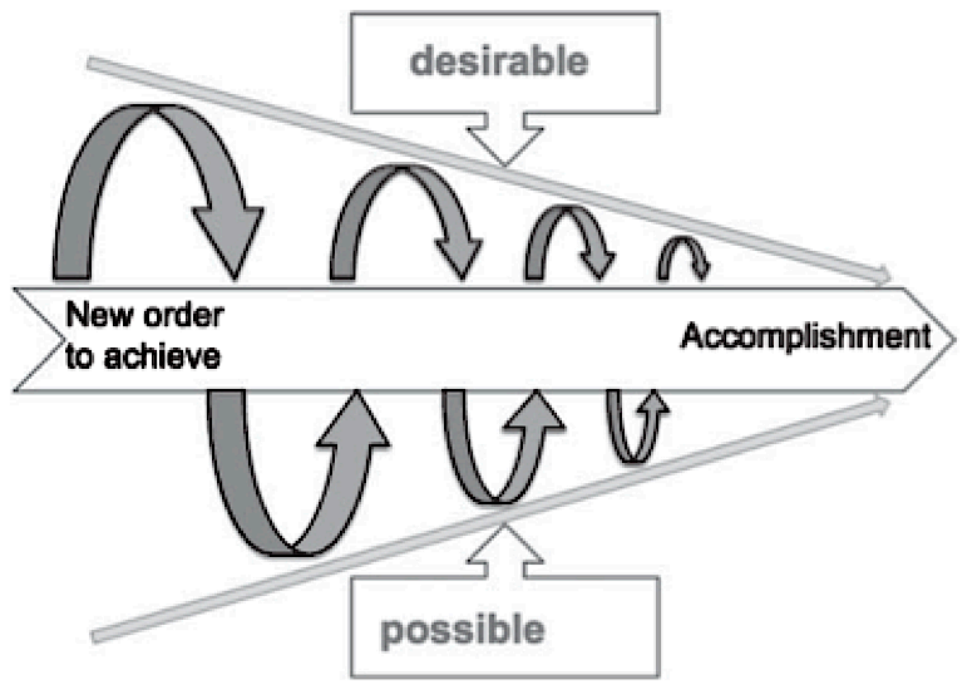

Fig. 1. Design as an articulation process between "desirable" and "possible" (according to Béguin [16]).

This frame of interpretation gives a place to work activities and professional transitions, provided the following two premises are accepted:

- First premise: A desirable innovation is ultimately intended to be implemented. A desirable is doomed to fail if there is no prospect of actualisation, including in a work activity. And in order to give the activity a place, methodological simulation protocols can be developed, within which the desirable will be implemented in (and confront to) the work activity, in order to objectify what is possible or impossible in the work.

- Second premise: this diagram suggests that the desirable is not built once and for all at the start of the design process. Certainly, there is an initial impulse. But the initial desirable will be reconfigured and redefined due to the resistance encountered during its implementation. There is therefore a process of unveiling, where what will be designed emerges as the process unfolds. The integration of considerations surrounding the possibilities and impossibilities of the work, through simulations - see above -, allows issues surrounding professional transitions to be integrated into the orientation of design action.

The example from energy efficiency in industry illustrates these premises. Energy efficiency was initially developed in France based on the opportunities afforded by new "smart" metres. These metres were initially expected to allow electricity distributors to adjust (or even stop completely) the electricity delivered to users based on their consumption. 
However, the installation of these meters carried out as an experiment on pilot sites (simulation) revealed many impossibilities in the work of installers. In addition to the fact that this installation was very costly for operators - who did not necessarily have the necessary skills or tools -, the connection between the meters and the equipment which the meter had to steer-proved extremely uncertain due to issues with interfacing between networks of different generations. A decision was made to reorient action. The electricity supplier gave up on the idea of adjusting the electricity supplied on its own, and shifted to a service-oriented approach: using consumption measurements provided by meters to advise customers on reducing their energy consumption. This orientation will lead to many changes in the professional worlds involved, but its implementation within the work ultimately proved possible.

We believe that ergonomics could make a key contribution by supporting the implementation of such a design process, which we call "step-by-step". This is a "stepby-step" approach insofar as the transition is carried out using "scenario-building" stages (steps), during which the ideas associated with the desirable are formatted as quickly as possible in concrete situations so that they can be confronted with the work and the work activity. The experience acquired in such a process constitutes a substrate from which the initial orientations are evaluated, and which can lead to new orientations that respond to the project.

\subsection{Set up a work observatory}

Our second proposal is to set up what we call a "work observatory", to address two issues. The first is that work, and in particular work activity, is largely made invisible (see also Nardi and Engeström, [20]). In many situations, people and the work they do are in fact made invisible because, instead of a detailed understanding of the work and the problems encountered by workers, procedures based on formal indicators are defined. The objective is therefore to reveal (to make visible) the work issues encountered during professional transitions. The second reason is that the experience resulting from the "scenarios" is in fact a substrate, a material that calls for the implementation of a reflexive process of analysis, shaping and objectification.

In order to contribute to this revealing and objectification, the work observatory can concretely rely on the following sequence:

- Identify locks. A lock can be defined as an obstacle, a resistance to reality, a breakdown in the sense of Bødker \& Klokmose [21], which causes an interruption in the course of professional activity, and which calls for a process of resolution (individual or collective). In terms of professional transitions, locks reveal what, in the routine and implicit of a professional world, does not work. As such, they are just as much markers of professional transitions as they are motors in that they potentially designate what needs to be solved. The idea is therefore to identify the locks that are encountered during the scenarios, and to document them (by observing the facts) in order to constitute a corpus for the next phase. 
- Set up debriefings. Debriefings consist of an ex-post analysis of the locks, based on the corpus previously mentioned. The central idea is that it is difficult to be in action and to understand what is happening there. One of the challenges of simulation situations is precisely to allow these analyses a posteriori, and even to equip this reflexive feedback. Debriefings are therefore intended to revert to the lock after the fact, in order to construct an interpretation. Debriefing analysis shows that this is a relatively complex process. Initially, the protagonists begin to transform a relatively informal experience into a narrative about the circumstances and critical episodes that form the very knot of the action. In a second stage, the protagonists move from the narrative to a "plot", that which is problematic or must be solved. And it is only then that a resolution, a possible outcome is identified.

- Consolidate the actions to be implemented. It is only once the debriefings are completed that it becomes possible to draw a set of lessons. Typically, this step takes the following form: one has observed such thing(s), one can draw such(s) lessons. What individual or collective decisions are made? In concrete terms, this last sequence can range from the identification of new intangible resources (e.g. acquisition of new knowledge) or material resources (tools) to be tested, to a redefinition of the desirable. But in all cases, it ends with the definition of new scenarios.

Beyond this factual description, two elements deserve to be highlighted. The first is that this observatory of work is in no way comparable to a classical discussion space, precisely because it rests on the ergonomist's ability to constitute a reflexive space focused on the analysis of what we have called the "locks". The debriefing phase shows that it is not at all straightforward to conduct this analysis, insofar as it is precisely what escapes the protagonists who are questioned. Such a process needs to be very seriously supported by facts, of which a record must be kept. The ability of the ergonomist to document this collective analysis is therefore essential. The second point is that this is a collective process. There are therefore questions relating to living together, relations between actors and knowledge-power relations. As such, it is based on a serious ability of the ergonomist to manage situations of conflict, disagreement and authority between the protagonists.

\section{Conclusion}

In this communication, our objective was to describe a focal point (the professional transitions embarked on at the level of the work activity), and to indicate the actions that we develop to facilitate them (to support). However, this orientation raises many questions.

One of these questions concerns the conditions for the implementation of such projects. We have argued above that professional transitions are based on "scenarios", i.e. situations specifically created for the purpose of building and developing experience. 
But it appears that these situations must be sufficiently protected from the constraints, the rhythms, the immediate stakes of production and even the major political form of work situations (subordination). Otherwise, it is impossible to carry out collective experiments that could in turn fertilise the daily production sites. In fact, it seems to us that such situations are similar in many respects to what Foucault [22] referred to as "heterotopias", that is, different places, which are certainly within a society, but which make it possible to experience concrete utopias because they obey different rules. It is in this perspective that our current work focuses on "demonstrators", "fablabs", "living labs" and even "virtual environments". These situations, which are sometimes referred to as "third places", appear to be original and fruitful forms of simulation.

\section{References}

1. Gazier, B.: Marchés transitionnels du travail et restructurations : vers une gestion collective des transitions. La Revue de l'Ires, (1,47). DOI : 10.3917/rdli.047.0301, (2005).

2. Moreau, M.A.:Normes sociales, droit du travail et mondialisation: confrontations et mutations. Paris, Dalloz, 2006.

3. Mathieu, C., Sterdyniack, H.: Le modèle social européen et l'Europe sociale. Revue de l'OFCE. $(1,104)$. DOI : 10.3917/reof.104.0043, (2008).

4. Daniellou, F.:The French-speaking ergonomists' approach to work activity: cross influences of field intervention and conceptual models. Theoretical Issues in Ergonomics Science, 6 (5), 409-427. https://doi.org/10.1080/14639220500078252, (2005).

5. Béguin, P.:Taking activity into account during the design process. @ctivités, 4(2), 115-121. https://journals.openedition.org/activites/1727 DOI : 10.4000/activites.1727, (2007).

6. Rabardel, P., Béguin, P.: Instrument mediated activity: from subject development to anthropocentric design. Theoretical Issues in Ergonomics Science 6 (5), 429-461 https://doi.org/10.1080/14639220500078179, (2005).

7. Béguin, P., Pueyo, V.: Quelle place au travail des agriculteurs dans la fabrication d'une agriculture durable. Pistes $(13,1)$, http://www.pistes.uqam.ca/v13n1/articles/v13n1a1.htm, (2011).

8. Béguin, P., Coutarel, L., Prost, L.: Conduire des projets innovants dans les BAC Grenelle pour réduire les risques environnementaux. $46^{\text {ème }}$ Congrès de la SELF, "L'ergonomie à la croisée des risques", Paris, 14-16 Septembre 2011, (2011).

9. Boudra, L., Béguin, P.: Analyzing territorial governance to prevent occupational risks in the sector of waste management. In Ergonomics challenges in the new economy. Proceeding of the 11th International Symposium on Human Factors in Organisational Design and Management and 46th Annual Nordic Ergonomics Society Conference. Broberg \& Al. (eds) 17-20 Août 2014, pp. 115-120, (2014).

10. Gotteland, C., Rosier, A., Pueyo, V., Béguin, P.: Supporting energy transitions. Project management as a learning device and accompanying professional transitions. Proceedings $19^{\text {th }}$ Triennial Congress of the IEA, Melbourne 9-14 August 2015, pp 435-439, (2015).

11. Norman, D.A.: Things that Make us Smart. Defending Human Attributes in the Age of the Machine (New York: Addison Wesley), (1992). 
12. Lomov, B.F.: O putyakh postroeniya teorii inzhenernoj psikhologii na osnove sistemnogo podkhoda. In Inzhenernaya Psikhologiya (Engineering Psychology), B.F. Lomov, V.F. Rubakhin and V.F. Venda (Eds), pp. 31-54 (Moscow: Nauka), (1977).

13. Meynard J.M., Aggeri F., Coulon J.B., Habib R., Tillon J.P.: Recherches sur la conception de systèmes agricoles innovants. Rapport INRA, (2006).

14. Le Masson, P., Weil, B., Hatchuel, A.: Les processus d'innovation. Conception innovante et croissance des entreprises. Paris : Hermès - Lavoisier, (2006).

15. Constant, E.: A model for technological change applied to the turbojet revolution. Technology and Culture. 14, 554-579, (1973).

16. Béguin, P.: Conduite de projet et fabrication collective du travail: une approche développementale. Document de synthèse en vue de l'habilitation à diriger des recherches. Université Victor Segalen, Bordeaux 2. 149 pages, (2010).

17. Bucciarelli, L.: Designing engineers. Cambridge : MIT Press, (1994).

18. Kaptelinin V.:The Object of Activity: Making Sense of the Sense-Maker. Mind, culture and activity. 2005; 12(1):4-18. https://doi.org/10.1207/s15327884mca1201_2, (2005).

19. Schön, D.: Educating the reflexive practitionner. San Francisco : Jossey-Bass, (1988).

20. Nardi, B., Engeström, Y.:A Web on the Wind: The Structure of Invisible Work. Computer Supported Cooperative Work 8: pp. 1-8. DOI : 10.1023/A:1008694621289, (1999).

21. Bødker, S., Klokmose, C.N.: Dynamics in artifact ecologies. Proc. of the 7th Nordic Conference on Human-Computer Interaction: Making Sense Through Design. ACM, New York, 2012, 448-457. DOI : 10.1145/2399016.2399085, ((2012).

22. Foucault, M.: Des espaces autres. Architecture, Mouvement, Continuité, $(5,1984)$, pp. 4649, (1984). 